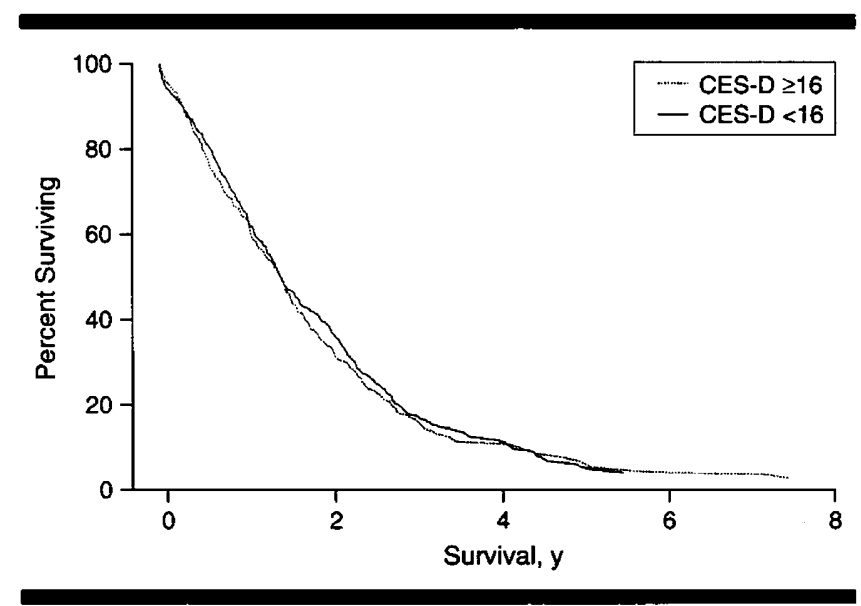

Time to death by depression status at visit within 6 months before acquired immunodeficiency syndrome. CES-D indicates Center for Epidemiologic Studies Depression Scale score.

was 18 months for the entire group. The Kaplan-Meier curves for the depressed and nondepressed groups (Figure) were compared using the log rank procedure $(P=.49)$. The finding from the multivariate Cox model showed a risk hazard for those with CES-D score of 16 or higher having a shorter time to death of 1.08 (95\% confidence interval, 1.34 to 0.81 ). Analyses defining depression in other ways based on CES-D score ${ }^{1}$ or based on a visit within 6 months after AIDS showed similar results.

We conclude that there is no evidence that depression is associated with a worse survival in HIV infection at any disease stage. This further supports our previous findings $s^{1,2}$ and agrees with the finding by Burack et $\mathrm{al}^{4}$ that the association between depression and decline in CD4 cell count does not directly affect survival. It is important to replicate these findings using standardized psychiatric diagnosis. Depression occurs among $4 \%$ to $30 \%$ of HIV-infected persons, and it is a serious condition that causes impaired functioning and increased risk for suicide. ${ }^{1}$ Depression among HIV-infected persons should be identified and treated aggressively.

Constantine G. Lyketsos, MD, MHS

Donald R. Hoover, $\mathrm{PhD}, \mathrm{MPH}$

Marcella Guccione, MS

The Johns Hopkins University

Baltimore, Md

This study was supported by grant MH 52507, from the National Institute of Mental Health, Bethesda, Md, and contracts NO1-A1-32535, NO1-A1-72631, NO1-A1-72634, NO1-A1-72676, and 5MO1-RR-00722 from National Institute of Allergy and Infectious Diseases, Bethesda, Md.

1. Lyketsos CG, Hoover DR, Guccione M, et al. Depressive symptoms as predictors of medical outcomes in HIV infection. JAMA. 1993;270:2563-2567.

2. Lyketsos CG, Hoover DR, Guccione M. Depression and CD4 decline. JAMA. 1994;271:1743-1744.

3. Hoover DR, Saah A, Bacellar H, et al. The progression of untreated HIV-1 infection prior to AIDS. Am J Public Health. 1992;82:1538-1541.

4. Burack JH, Barrett DC, Stall RD, Chesney MA, Ekstrand ML, Coates TJ. Depressive symptoms and CD4 lymphocyte decline among HIV-infected men. JAMA 1993;270:2568-2573.

5. Lyketsos CG, Federman EB. Psychiatric disorders and HIV infection: impact on one another. Epidemiol Rev. 1995;17:152-164.

\section{HIV-1 Shedding and Chlamydial Urethritis}

To the Editor.-Drs Schmid and Fontanarosa ${ }^{1}$ thoroughly discussed the causes and management of nongonococcal urethritis. However, they did not emphasize the link between treatment of sexually transmitted diseases and prevention of human immunodeficiency virus (HIV). ${ }^{2}$ We collected ejaculate from a 32-year-old white man with HIV-1 disease and a CD4 cell count of $0.11 \times 10^{9} / \mathrm{L}$ who was taking no antiretroviral therapy. The patient had chlamydial urethritis at the time the sample was obtained, with dysuria but without discharge. We performed quantitative HIV-1 culture on his seminal cell fraction, using a modification of the AIDS Clinical Trials Group quantitative cell culture protocol. We had previously performed 32 quantitative cultures for HIV-1 using seminal cells from $25 \mathrm{HIV}$-1-infected individuals; the range of excretion was $<3.0$ to 2523.3 infectious units per ejaculate. Our patient excreted 6729 infectious units of HIV-1 in his ejaculate obtained at the time of chlamydial infection $(P<.001$ for the comparison of subjects without symptoms of urethritis vs subjects with symptomatic urethritis). We also analyzed the seminal plasma by reverse transcriptase polymerase chain reaction, using a commercial assay (HIV-1 Amplicor Monitor, Roche Biomedical Laboratories, Research Triangle Park, NC). The patient excreted 375000 copies of HIV-1 RNA per milliliter of seminal plasma. Four weeks after the patient completed therapy for chlamydial infection, we reexamined the semen for HIV-1. The quantitative culture could not be done. However, the copies of HIV-1 RNA in the seminal plasma at this time were reduced to 7500 per milliliter. Using an alternative amplification method that uses silica beads to separate HIV-1 RNA from potential inhibitors, ${ }^{3}$ the results from the pretreatment and posttreatment samples were 1200000 and 12000 copies per milliliter, respectively. The patient received no antiretroviral therapy during this interval. These results suggest chlamydial urethritis may increase shedding of HIV-1 in semen, and treatment of chlamydial urethritis may decrease shedding of HIV-1. Moss and coworkers ${ }^{4}$ have reported that treatment of gonococcal urethritis in HIVpositive men decreases detection of HIV-1 in urethral swab specimens. These observations provide biological support to the recent observation that aggressive therapy for sexually transmitted diseases reduces transmission of HIV. ${ }^{5}$
Joseph J. Eron, Jr, MD
Bruce Gilliam, MD
Susan Fiscus, $\mathrm{PhD}$
John Dyer, MD
Myron S. Cohen, MD
University of North Carolina at Chapel Hill

This research was supported in part by grant UO1-AI25868-09 from the National Institutes of Health. Assay materials were provided by Roche Biomedical Laboratories, Research Triangle Park, NC, and Organon-Technika, Durham, NC.

1. Schmid GP, Fontanarosa PB. Evolving strategies for management of the nongonococcal urethritis syndrome. JAMA. 1995;274:577-579.

2. Cohen MS, Dallabetta G, Laga M, Holmes KK. A new deal in HIV prevention: lessons from the global approach. Ann Intern Med. 1994;120:340-341.

3. van Gemen B, van Beuningen $R$, Nabbe A, et al. A one-tube quantitative HIV-1 RNA NASBA nucleic acid amplification assay using electrochemiluminescent (ECL) labeled probes. J Virol Methods. 1994;49:157-167.

4. Moss GB, Overbaugh J, Welch M, et al. Human immunodeficiency virus DNA in urethral secretions in men: association with gonococcal urethritis and CD4 cell depletion. $J$ Infect Dis. In press.

5. Grosskurth H, Mosha F, Todd E, et al. Impact of improved treatment of sexually transmitted diseases on HIV infection in rural Tanzania: randomized controlled trial. Lancet. 1995;346:530-536.

\section{CORRECTION}

Incorrect Reference Citations in Text.-In the Letters entitled "The Relationship Between Physicians' Malpractice Claims History and Later Claims," published in the May 17, 1995, issue of THE JOURNAL (JAMA. 1995;273:1487-1489), the reference citations in the text of the reply by Messrs Bovbjerg and Petronis were incorrect. The first citation to reference 1 was correct; reference 2 should have been cited after the second and third sentences of the second paragraph; reference citations $2,3,4$, and 5 should have been citations 3 , 4,5 , and 6 , respectively; and reference 6 should not have been cited in the sixth paragraph. 